\title{
Numerical study of the quenching of a laminar premixed hydrogen flame
}

\author{
Björn Pfeiffelmann, and Ali Cemal Benim* \\ Center of Flow Simulation (CFS), Department of Mechanical and Process Engineering, Düsseldorf University of Applied Sciences, \\ Münsterstr. 156, D-40476 Düsseldorf, Germany
}

\begin{abstract}
A numerical analysis of the quenching of a laminar, premixed hydrogen-air flame is presented. A global and a detailed reaction mechanism are considered. First, one-dimensional flame propagation is analyzed and the models are validated based on the predicted flame speed. Subsequently, the quenching near a solid wall of a duct is analyzed, within a two-dimensional, steady-state formulation. Finally, propagation of a flame front through a quenching mesh, within an unsteady, two-dimensional analysis is considered. It is observed that the global mechanism does not predict a quenching of the flame by the mesh, whereas the detailed mechanism does.
\end{abstract}

\section{Introduction}

Power generation by thermal machinery, including the gas turbine [1] and steam turbine [2] plants, largely depends on the conversion of the chemically bound energy by the combustion process. Parallel to the efforts for exploiting new energy sources, as well as recovery techniques [3], combustion continues to play an important role in power generation, also through the renewable energies, considering the significance of biomass in the latter.

Combustion of hydrogen and hydrogen-blend fuels plays an especially important role in clean and efficient energy supply, climate protection and resource efficiency. On the one hand, hydrogen represents an attractive alternative to storing excess energy in power generation from wind power or photovoltaics [4]. On the other hand, instead of combustion $[5,6]$ the gasification of biomass and coal is a good possibility for an efficient and clean power generation [7]. The gasification product, the synthesis gas contains, in addition to carbon monoxide and small amounts of methane, significant amounts of hydrogen. Additionally, there is a rapidly growing interest in hydrogen production using nuclear power plants, using the nuclear power for electrolysis, thermochemical cycles or hybrid approaches [8]. From an environmental point of view, the subsequent combustion of hydrogen is most welcome because it produces no carbon dioxide when burned.

Combustion of hydrogen has relevance also for safety engineering. Hydrogen has a high diffusivity and its leakage is more likely to be an issue compared to other gases. Hydrogen plays also a special role in conjunction with the safety of nuclear power plants. In nuclear reactors, metal components are cooled by light or heavy water. As consequence, the cooled metal parts corrode at some rate in the presence of intense radiation, which is accompanied by hydrogen gas production. Existence of hydrogen gas added to the liquid or steam coolant induces excess pressure in the steam line and has further negative effects such as deteriorating the heat transfer and the phase change processes, as well as embrittlement and swelling of the nuclear metals, thus, reduction in the power output and shortening of the reactor life. Thus, as a part of normal reactor operation, slightly radioactive hydrogen-steam mix is released from a cooler part of the line and captured for further treatment, which creates a safety issue in case of an accident.

Use of hydrogen or hydrogen blend gases as fuel in combustion systems represents a great challenge. Hydrogen is extremely reactive and, compared to other gases, has very different material properties, so that even relatively small proportions of hydrogen can greatly alter the combustion properties of the gas mixture.

Therefore, the combustion of fuel gas mixtures with hydrogen fractions requires new combustion chamber concepts. In power generation by combustion, the modern technology that is, in the meantime, state-of-theart for land-based gas turbine combustors is the so-called "lean premixed combustion", due to its high potential for achieving very low nitrogen oxide emissions. A principal problem in premixed combustion systems is the socalled "flashback" [9]. This means an undesirable flame propagation upstream, towards the inner parts of the burner, which cause serious damage [9].

A classical cause of flashback is an imbalance between the local flow velocity and flame speed, in the favor of the latter, which may be caused by a change/disturbance in the operation of the burner. This

\footnotetext{
*orresponding author: alicemal@ prof-benim.com
} 
aspect makes the use of hydrogen fuel in premixed combustion to become an especially great challenge, since the high reactivity of hydrogen considerably increases the flame speed and flashback propensity [9]. Thus, effective measures are needed to prevent an undesirable flame propagation in the combustion of hydrogen containing fuels. This is equally important as far as the above-mentioned safety issues are considered.

A measure to guard against undesirable flame propagation is the use of a so-called "quenching mesh" [9]. Here, although it is not the only cause, a primary cause that prevents the flame propagation can be considered to be the heat loss to the confining walls. A decrease of the temperature in the flame front retards the combustion reactions, and, thus, the flame propagation. A termination of the combustion reactions, as a result, is called "quenching" and the temperature that this occurs is called "quenching temperature". The range, within which the flame is quenched near the solid wall is termed as "quenching distance".

Thus, a solid mesh in the flow path, with mesh sizes smaller than the quenching distance can completely extinguish an upward propagating flame front and prevent flashback, which is the main idea behind the concept of "quenching mesh".

Although experimental values for quenching distances can be found in the literature [10], there is a need for a better understanding of the phenomenon with respect to the influence of different conditions such the geometry, mixture composition, fluid dynamic and thermodynamic conditions [11]. Until recently a number of further experimental [12] and theoretical [13] studies were performed on the subject. Computational investigations $[14,15]$ are, however, still rare and bound to simplifications leaving room for further exploration.

In the present study, the flow, heat and mass transfer processes for a hydrogen flame in the presence of a quenching mesh is investigated computationally. In the present study, a laminar flame is considered, first, concentrating on the chemical kinetics, and, excluding the additional challenges related with the modelling of turbulence [16-20], and of turbulence-chemistry interactions [21-22], at the present stage.

\section{Modelling}

In the present study, a hydrogen-air mixture under atmospheric pressure is considered, which is mixed in a stoichiometric ratio (i.e. the equivalence ratio $\varphi$ is unity, $\varphi=1.0)$ [23].

The continuity equation, the Navier-Stokes equations, the energy equation and species transport equations are solved for subsonic and laminar flow of the chemically reacting mixture, assuming an ideal gas behavior [23,24]. Buoyancy is neglected. The radiative heat transfer [25] is also omitted, as gas radiation is obviously weaker compared to radiation encountered in flames containing liquid droplets or solid particles such as pulverized coal flames [5]. Considering the multicomponent diffusion, the Soret and Dufour effects are also neglected, in the species transport and energy equations, respectively [23,24].

For the computational modelling, the finite volume method based, general-purpose CFD code ANSYS Fluent 18.0 [26] is used as the basic software platform. For the velocity-pressure coupling, the SIMPLEC [27] and PISO [28] schemes are used for steady-state and unsteady formulations, respectively. For unsteady calculations, a second-order accurate backward differencing scheme is used for the time discretization [29], whereas the time step-size is selected to assure the cell Courant number to be smaller than unity. For the discretization of the convective terms, a second-order accurate upwind scheme [30] is used for structured grids, whereas for the structured grids the QUICK scheme [31] is used, which is formally third-order accurate. In all cases grid independence studies are performed and grid independence is ensured.

The chemical kinetics software Cantera [32], is also employed in one-dimensional flame calculations for analyzing reaction mechanisms and verifying their implementation in Fluent [26].

\subsection{Material properties}

Laminar flame propagation, which is the key process in the present problem strongly depends on the material properties. Therefore, an accurate modelling in this respect is attempted. For all species, the specific heat capacities are represented by a pair of fourth order polynomials of temperature [33], one for the low $(300 \mathrm{~K}<\mathrm{T}<1000 \mathrm{~K})$ and the other for the high $(1000 \mathrm{~K}<\mathrm{T}<5000 \mathrm{~K})$ temperature range. The viscosities, thermal conductivities, and the multi-diffusion diffusion coefficients of all species are calculated according to the kinetic theory [33-35]. The mixture properties are calculated according to the mixing laws [23], based on the local composition.

\subsection{Reaction mechanisms}

Reaction rate coefficients are expressed by the Arrhenius equation [23]. For a general, reversible reaction between the two general reactants $M_{1}$ and $M_{2}$ (to form $M_{3}$ and $\mathrm{M}_{4}$ )

$$
\mathrm{n}_{1} \mathrm{M}_{1}+\mathrm{n}_{2} \mathrm{M}_{2} \leftrightarrow \mathrm{n}_{3} \mathrm{M}_{3}+\mathrm{n}_{4} \mathrm{M}_{4}
$$

where $\mathrm{n}_{1}, \mathrm{n}_{2}, \mathrm{n}_{3}, \mathrm{n}_{4}$ denote the stoichiometric coefficients, the rate constant of the forward reaction $\left(\mathrm{k}_{\mathrm{f}}\right)$ is expressed as

$$
\mathrm{k}_{\mathrm{f}}=A T^{\mathrm{n}} \exp \left(-\mathrm{E}_{\mathrm{a}} / \mathrm{R}_{\mathrm{u}} \mathrm{T}\right)\left[\mathrm{M}_{1}\right]^{\mathrm{n} 1}\left[\mathrm{M}_{2}\right]^{\mathrm{n} 2}
$$

In (2), $\mathrm{T}$ is the thermodynamic temperature, $\mathrm{E}_{\mathrm{a}}$ is the activation energy, $R_{u}$ is the universal gas constant, $A$ is the so-called pre-exponential factor, $\mathrm{n}$ is the so-called temperature exponent and the brackets indicate molar concentrations of the respective components. The rate constant of the backward reaction $\left(\mathrm{k}_{\mathrm{b}}\right)$ of the reversible 
reaction is calculated based on the equilibrium constant of the reaction [23]. Obviously, detailed reaction mechanisms $[36,37]$ that consist of elementary reactions are accurate and comprehensive, but, computationally not very convenient due to the usually large number of species involved that cause long computing times. Global and reduced mechanisms [36,37] are computationally more attractive as they comprise a much smaller number of species, allowing much shorter computational times. The penalty paid for this advantage is, nevertheless, a loss in the accuracy and/or universality as well as comprehension.

However, under certain conditions, for specific purposes, the global/reduced mechanisms can also deliver sufficiently accurate results. In the present study, two reaction mechanisms are selected, which, both, consist of reversible reactions. These are the single-step, global mechanism of Marinov et al. [38] and the detailed mechanism of Conaire et al. [39], which are summarized in Table 1 and Table 2, respectively.

Table 1. Global $\mathrm{H}_{2} / \mathrm{O}_{2}$ mechanism of Marinov et al. [38] (units: $\mathrm{cm}^{3}$, mol, $\mathrm{s}$, kcal, $\mathrm{K}$ )

\begin{tabular}{rrrrr}
\hline & Reaction & $\mathrm{A}$ & $\mathrm{n}$ & $\mathrm{E}_{\mathrm{a}}$ \\
\hline 1 & $2 \mathrm{H}_{2}+\mathrm{O}_{2}=2 \mathrm{H}_{2} \mathrm{O}$ & $1.80 \cdot 10^{13}$ & 0.00 & 34.98 \\
\hline
\end{tabular}

\subsection{Wall quenching}

Quenching of the flame by a wall is a complex phenomenon. Basically, two mechanisms have been stated, so far, to be responsible for this to occur [40]: I) Heat loss to the cold wall, II) Disturbance of the radical pool by the existence of the wall.

The opinion on the relative importance of these effects varies among the researchers [40]. The influence of the details of flow field in the wall boundary layer via flame stretch and curvature is, nevertheless, is addressed by neither of the two criteria. In the present study, mainly, the heat loss effect will be investigated. The modelling of the influence of the wall on the radical pool in the boundary layer is not a straightforward issue and will be investigated in the future studies.

\section{Results}

\subsection{One-dimensional laminar flame}

For the flashback phenomenon, the flame speed is a key parameter. As a basis validation, the propagation speed of an undisturbed (planar, unstretched) one-dimensional flame $\left(\mathrm{S}_{\mathrm{L}}{ }^{0}\right)$ is calculated with the global (Table 1, [38]) and detailed (Table 2, [39]) reaction mechanisms.

The predictions for a stoichiometric flame under standard conditions are compared with measurements in Table 3. One can see that the predicted flame speed by the detailed mechanism is well in the range of measured values, whereas the global mechanism overpredicts only slightly. The predicted profiles of temperature are
Table 2. Detailed $\mathrm{H}_{2} / \mathrm{O}_{2}$ mechanism of Conaire et al. [39] (units: $\mathrm{cm}^{3}$, mol, s, kcal, K)

\begin{tabular}{|c|c|c|c|c|}
\hline & Reaction & A & $\mathrm{n}$ & $\mathrm{E}_{\mathrm{a}}$ \\
\hline \multicolumn{5}{|c|}{$\mathrm{H}_{2} / \mathrm{O}_{2}$ Chain Reactions } \\
\hline 1 & $\mathrm{H}+\mathrm{O}_{2}=\mathrm{O}+\mathrm{OH}$ & $1.91 \cdot 10^{14}$ & 0.00 & 16.44 \\
\hline 2 & $\mathrm{O}+\mathrm{H}_{2}=\mathrm{H}+\mathrm{OH}$ & $5.08 \cdot 10^{4}$ & 2.67 & 6.292 \\
\hline 3 & $\mathrm{OH}+\mathrm{H}_{2}=\mathrm{H}+\mathrm{H}_{2} \mathrm{O}$ & $2.16 \cdot 10^{8}$ & 1.51 & 3.43 \\
\hline 4 & $\mathrm{O}+\mathrm{H}_{2} \mathrm{O}=\mathrm{OH}+\mathrm{OH}$ & $2.95 \times 10^{6}$ & 2.02 & 13.40 \\
\hline \multicolumn{5}{|c|}{$\mathrm{H}_{2} / \mathrm{O}_{2}$ Dissociation/Combination Reactions } \\
\hline $5^{\mathrm{a}}$ & $\mathrm{H}_{2}+\mathrm{M}=\mathrm{H}+\mathrm{H}+\mathrm{M}$ & $4.57 \cdot 10^{19}$ & -1.40 & 105.1 \\
\hline $6^{\mathrm{a}}$ & $\mathrm{O}+\mathrm{O}+\mathrm{M}=\mathrm{O}_{2}+\mathrm{M}$ & $6.17 \cdot 10^{15}$ & -0.50 & 0.00 \\
\hline $7^{\mathrm{a}}$ & $\mathrm{O}+\mathrm{H}+\mathrm{M}=\mathrm{OH}+\mathrm{M}$ & $4.72 \cdot 10^{18}$ & -1.00 & 0.00 \\
\hline $8^{b}$ & $\mathrm{H}+\mathrm{OH}+\mathrm{M}=\mathrm{H}_{2} \mathrm{O}+\mathrm{M}$ & $4.50 \cdot 10^{22}$ & -2.00 & 0.00 \\
\hline \multicolumn{5}{|c|}{ Formation and Consumption of $\mathrm{HO}_{2}$} \\
\hline \multirow[t]{2}{*}{$9^{c}$} & $\mathrm{H}+\mathrm{O}_{2}+\mathrm{M}=\mathrm{HO}_{2}+\mathrm{M}$ & $3.48 \cdot 10^{16}$ & -0.41 & -1.12 \\
\hline & $\mathrm{H}+\mathrm{O}_{2}=\mathrm{HO}_{2}$ & $1.48 \cdot 10^{12}$ & 0.60 & 0.00 \\
\hline 10 & $\mathrm{HO}_{2}+\mathrm{H}=\mathrm{H}_{2}+\mathrm{O}_{2}$ & $1.66 \cdot 10^{13}$ & 0.00 & 0.82 \\
\hline 11 & $\mathrm{HO}_{2}+\mathrm{H}=\mathrm{OH}+\mathrm{OH}$ & $7.08 \cdot 10^{13}$ & 0.00 & 0.30 \\
\hline 12 & $\mathrm{HO}_{2}+\mathrm{O}=\mathrm{OH}+\mathrm{O}_{2}$ & $3.25 \cdot 10^{13}$ & 0.00 & 0.00 \\
\hline 13 & $\mathrm{HO}_{2}+\mathrm{OH}=\mathrm{H}_{2} \mathrm{O}+\mathrm{O}_{2}$ & $2.89 \cdot 10^{13}$ & 0.00 & -0.50 \\
\hline \multicolumn{5}{|c|}{ Formation and Consumption of $\mathrm{H}_{2} \mathrm{O}_{2}$} \\
\hline \multirow[t]{2}{*}{14} & $\mathrm{HO}_{2}+\mathrm{HO}_{2}=\mathrm{H}_{2} \mathrm{O}_{2}+\mathrm{O}_{2}$ & $4.20 \cdot 10^{14}$ & 0.00 & 11.98 \\
\hline & $\mathrm{HO}_{2}+\mathrm{HO}_{2}=\mathrm{H}_{2} \mathrm{O}_{2}+\mathrm{O}_{2}$ & $1.30 \cdot 10^{11}$ & 0.00 & -1.629 \\
\hline \multirow[t]{2}{*}{$15^{\mathrm{d}}$} & $\mathrm{H}_{2} \mathrm{O}_{2}+\mathrm{M}=\mathrm{OH}+\mathrm{OH}+\mathrm{M}$ & $1.27 \cdot 10^{17}$ & 0.00 & 45.5 \\
\hline & $\mathrm{H}_{2} \mathrm{O}_{2}=\mathrm{OH}+\mathrm{OH}$ & $2.95 \cdot 10^{14}$ & 0.00 & 48.4 \\
\hline 16 & $\mathrm{H}_{2} \mathrm{O}_{2}+\mathrm{H}=\mathrm{H}_{2} \mathrm{O}+\mathrm{OH}$ & $2.41 \cdot 10^{13}$ & 0.00 & 3.97 \\
\hline 17 & $\mathrm{H}_{2} \mathrm{O}_{2}+\mathrm{H}=\mathrm{H}_{2}+\mathrm{HO}_{2}$ & $6.03 \cdot 10^{13}$ & 0.00 & 7.97 \\
\hline 18 & $\mathrm{H}_{2} \mathrm{O}_{2}+\mathrm{O}=\mathrm{OH}+\mathrm{HO}_{2}$ & $9.55 \cdot 10^{6}$ & 2.00 & 3.97 \\
\hline \multirow[t]{2}{*}{19} & $\mathrm{H}_{2} \mathrm{O}_{2}+\mathrm{OH}=\mathrm{H}_{2} \mathrm{O}+\mathrm{HO}_{2}$ & $1.00 \cdot 10^{12}$ & 0.00 & 0.00 \\
\hline & $\mathrm{H}_{2} \mathrm{O}_{2}+\mathrm{OH}=\mathrm{H}_{2} \mathrm{O}+\mathrm{HO}_{2}$ & $5.80 \cdot 10^{14}$ & 0.00 & 9.56 \\
\hline $\mathrm{a}$ & \multicolumn{4}{|c|}{ Efficiency factors: $\mathrm{H}_{2} \mathrm{O}=12.0 ; \mathrm{H}_{2}=2.5$} \\
\hline $\mathrm{b}$ & \multicolumn{4}{|c|}{ Efficiency factors: $\mathrm{H}_{2} \mathrm{O}=12.0 ; \mathrm{H}_{2}=0.73$} \\
\hline $\mathrm{c}$ & \multicolumn{4}{|c|}{ Troe param.: $\mathrm{a}=0.5, \mathrm{~T}^{* * *}=10^{-30}, \mathrm{~T}^{* *}=10^{30}, \mathrm{~T}^{*}=10^{100}$} \\
\hline & \multicolumn{4}{|c|}{ Efficiency factors: $\mathrm{H}_{2} \mathrm{O}=14.0 ; \mathrm{H}_{2}=1.3$} \\
\hline $\mathrm{d}$ & \multicolumn{4}{|c|}{ Troe param.: $\mathrm{a}=0.5, \mathrm{~T}^{* * * *}=10^{-30}, \mathrm{~T}^{* *}=10^{30}$} \\
\hline & \multicolumn{4}{|c|}{ Efficiency factors: $\mathrm{H}_{2} \mathrm{O}=12.0 ; \mathrm{H}_{2}=2.5$} \\
\hline
\end{tabular}

Table 3. Predicted and measured $\mathrm{S}_{\mathrm{L}}{ }^{0}(\mathrm{~m} / \mathrm{s})$ for stoichiometric flame under standard conditions.

\begin{tabular}{cccc}
\hline & $\begin{array}{c}\text { Global mech. } \\
\text { (Table 1) }\end{array}$ & $\begin{array}{c}\text { Detailed mech. } \\
\text { (Table 2) }\end{array}$ & $\begin{array}{c}\text { Exp. } \\
{[38]}\end{array}$ \\
\hline $\mathrm{S}_{\mathrm{L}}{ }^{0}(\mathrm{~m} / \mathrm{s})$ & 2.8 & 2.3 & $2.0-2.5$ \\
\hline
\end{tabular}

presented in Figure 1. One can observe that the temperature profile is predicted much sharper by the global mechanism, compared to the detailed one.

\subsection{Flame stabilized in a channel}

As next step, a steady-state, two-dimensional formulation is applied. A laminar, stoichiometric, premixed $\mathrm{H}_{2}$ /Air flame stabilized in the entrance region of a channel is considered. The channel has an inlet height of $6 \mathrm{~mm}$, and a length of $8 \mathrm{~mm}$. For enhancing flame stabilization, a diffuser-like, slightly diverging channel is considered, with an expansion angle of $4^{\circ}$. The boundaries of the solution domain are the symmetry plane, channel wall, inlet and outlet boundaries. At the 


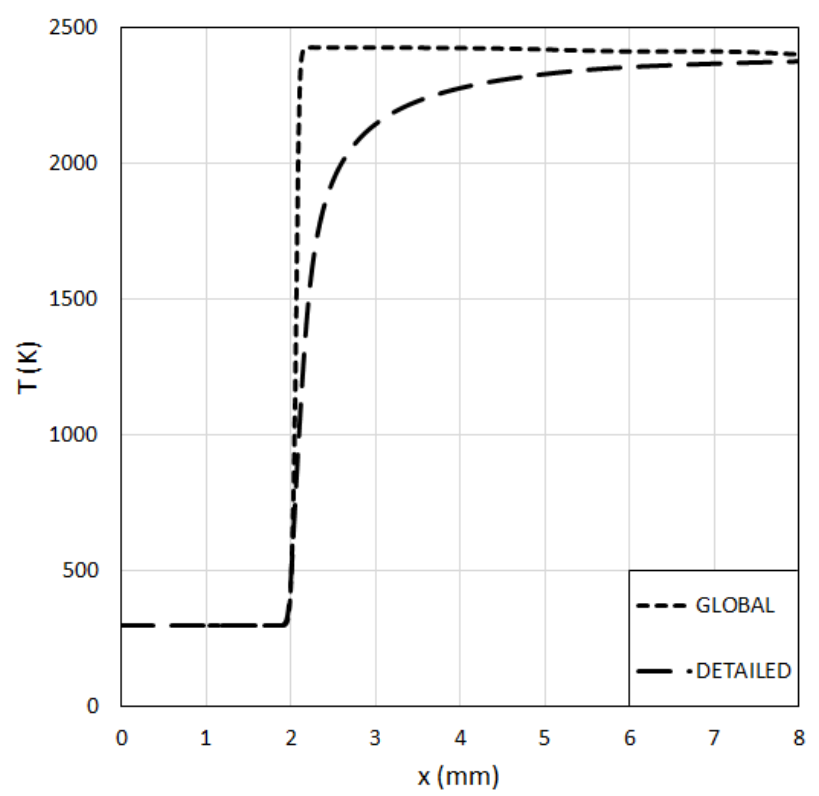

Figure 1. Temperature profiles for 1D flame.

inlet the stoichiometric mixture enters into the channel with a velocity slightly higher than the laminar flame speed, and a temperature of $300 \mathrm{~K}$. The wall temperature is also set to $300 \mathrm{~K}$. The predicted fields of the static temperature (in $\mathrm{K}$ ) by the two reaction mechanisms are shown in Figure 2.

The temperature boundary layer near the cold diffuser wall can be seen in the figure. The low temperatures lead to a retardation of the combustion reactions and a local quenching. The present configuration is different from the experimental configurations at which the quenching distances are measured $[10,40]$.

However, one can still see the qualitative behavior of different reaction mechanisms in predicting the quenching distance. One can see in the figure that the quenching effect by the cold wall is predicted to a stronger extent by the detailed mechanism (Fig. 2b) compared to the global one (Fig. 2a).

An indication for the implied quenching distance can be deduced by applying a rather simple criterion suggested by Zeldovich (cited in [15]), based on a single-step global mechanism, where the local flame temperature at which quenching shall occur $\left(\mathrm{T}_{\mathrm{q}}\right)$ is estimated by

$$
\mathrm{T}_{\mathrm{q}}=\mathrm{T}_{\mathrm{ad}}-\frac{\mathrm{T}_{\mathrm{ad}}^{2}}{\mathrm{E}_{\mathrm{a} / \mathrm{R}_{\mathrm{u}}}}
$$

where $\mathrm{T}_{\mathrm{ad}}$ denotes the adiabatic flame temperature. The implied quenching distances $\left(\delta_{\mathrm{q}}\right)$ that result by applying this criterion to both solutions (Fig. 2) at the flame front are presented in Table 4 (using the activation energy, $E_{a}$, of the global mechanism reaction from Table 1, for the both cases). One can see that the quenching distance implied by the detailed mechanism is in the range of experimental values that have been usually observed.

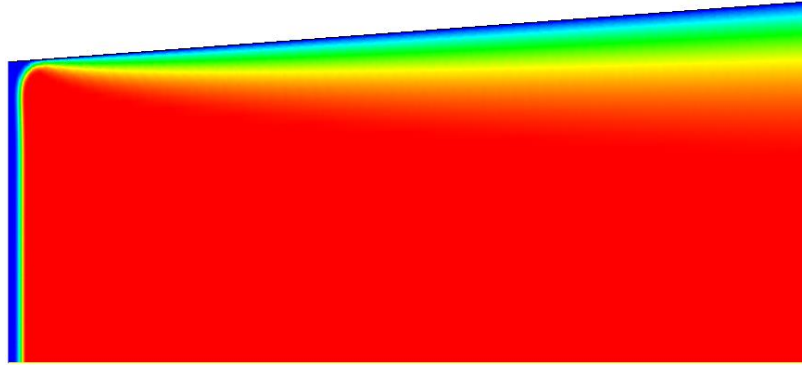

(a)

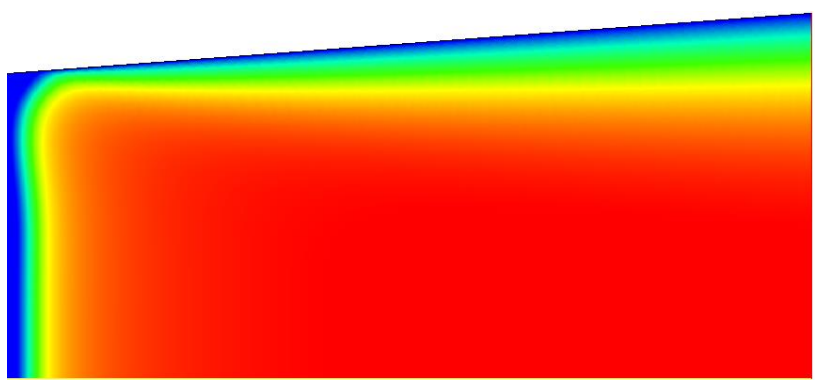

(b)

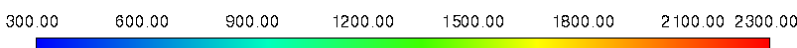

Figure 2. Predicted fields of static temperature (in K) for flame stabilized near the inlet of a diverging duct (a) global mechanism (Table 1), (b) detailed mechanism (Table 2)

Table 4. Implied quenching distances.

\begin{tabular}{ccc}
\hline & $\begin{array}{c}\text { Global mechanism } \\
(\text { Table } 1)\end{array}$ & $\begin{array}{c}\text { Detailed mechanism } \\
\text { (Table 2) }\end{array}$ \\
\hline$\delta_{\mathrm{q}}(\mathrm{mm})$ & 0.1 & 0.6 \\
\hline
\end{tabular}

\subsection{Flame passing a quenching mesh}

As a further step, flame propagation through a quenching mesh is analyzed within an unsteady, two-dimensional formulation. A quenching mesh consisting of cylindrical wires is considered. The configuration is the same as the one analyzed by Kudriakov et al. [15], using a different global mechanism. The wire diameter (D) is assumed to be 0.3 , which is also taken to be the spacing between the wires. Using the symmetries in the configuration, the solution domain is defined as shown in Figure 3.

The initially non-reacting, quiescent stoichiometric $\mathrm{H}_{2}$ /Air mixture at atmospheric pressure and $300 \mathrm{~K}$ in the domain is instantaneously ignited and the flame propagation in the domain is calculated. The initial ignition zone is also indicated in the figure.

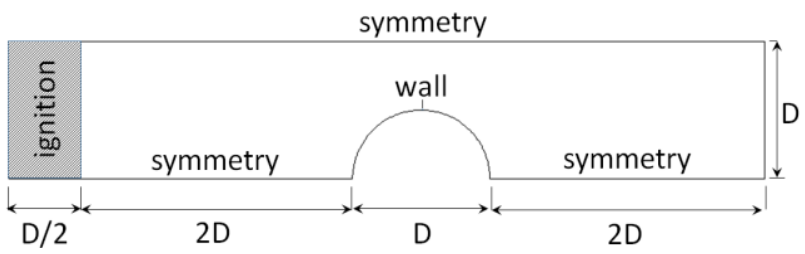

Figure 3. Solution domain 
The cylinder wall is kept at $300 \mathrm{~K}$ during the process. It is arguable that the cylinder does not remain at its initial temperature but get heated during the process. However, using an estimated convective heat transfer coefficient based on the laminar flame speed, material properties of steel and applying the block capacity method (which is applicable as the Biot number is well below 0.1 ) one can calculate the estimated temperature change of the wire to be less than $1 \mathrm{~K}$ within the time required the flame front to pass over the wire. Thus, the assumption of a constant wall temperature can be seen to be realistic.

In generating the computational mesh, principally an equidistant mesh distribution is applied. The mesh size is set to be $0.005 \mathrm{~mm}$ everywhere and in some places (e.g. on the cylinder surface) slightly smaller. Looking at the flame structure shown in Fig. 1, one can deduce that this mesh size provides a sufficient resolution to resolve the flame front (this was additionally ensured by a grid independence study for the present case). The mesh consists mainly of triangular cells, which are complemented by a layer of quadrangles along the cylinder wall. The total number of cells is above 40,000, which is nearly four times finer than the one used by Kudriakov et al. [15].

The temperature fields calculated by the global (Table 1) and detailed reaction (Table 2) mechanism for the instant of $125 \mu$ s after ignition are presented (in K) in Figure 4. According to the global mechanism (Fig. 4a) the flame front propagates towards the quenching mesh (from left to right) and can pass through the mesh, indicating that the mesh (which has a gap width of 0.3 $\mathrm{mm}$ ) is not able to protect the unburnt mixture behind the mesh from ignition. However, according to the detailed reaction mechanism (Fig. 4b) reactions slow down and the flame gets quenched, implying that the quenching mesh is able to protect the unburnt mixture.

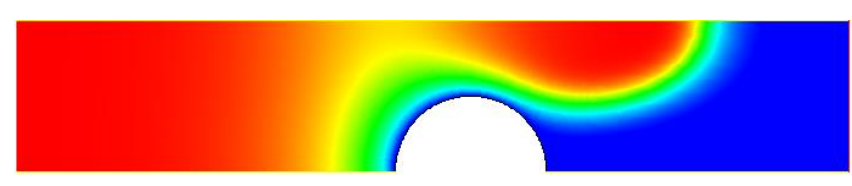

(a)

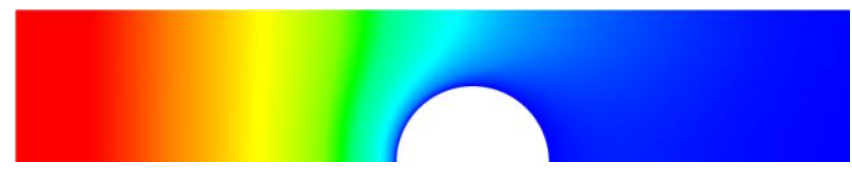

(b)

Figure 4. Predicted temperature fields $125 \mu$ s after ignition (a) global mechanism (Table 1) (b) detailed mechanism (Table 2)

\section{Conclusions}

A numerical analysis of the quenching of a premixed hydrogen-air flame is presented. The analysis is confined to laminar flames. As combustion mechanism, a global, and a detailed reaction mechanism are considered. First, one-dimensional flame propagation is analyzed and the computational models are validated by comparing the predicted flame speed with the measured values. Subsequently, the quenching near a solid wall of a duct is analyzed, within a two-dimensional, steady-state formulation. Finally, propagation of a flame front through a quenching mesh with a gap width of $0.3 \mathrm{~mm}$ is investigated, within an unsteady, two-dimensional analysis. It is observed that the global mechanism does not predict a quenching of the flame, by the mesh, whereas the detailed mechanism predicts a quenching. More detailed studies will be performed in the future work.

\section{References}

1. A. C. Benim, D. Brillert, M. Cagan, ASME Paper No. GT2004-54151, in: Proc. ASME Turbo Expo 2004, Vienna, Austria, 4, pp. 453-460 (2004)

2. A. C. Benim, M. Geiger, S. Doehler, M. Schoenenberger, H. Roemer, Modelling the flow in the exhaust hood of steam turbines under consideration of turbine-exhaust hood interaction, (in: Proceed. 1st European. Conf. Turbomachinery Fluid Dynamic and Thermodynamic Aspects: Computational. Methods, Erlangen, Germany, Book Series: VDI Berichte, Vol.1185, pp.343-357, VDI Verlag, Duesseldorf, 1995)

3. D. G. Ebling, A. Krumm, B. Pfeiffelmann, J. Gottschald, J. Bruchmann, A. C. Benim, M. Adam, R. Labs, R. R. Herbertz, A. Stunz, Journal of Electronic Materials, 45, 7, pp.3433-3439 (2016)

4. M. Götz, J. Lefebvre, F. Mörs, A. McDaniel Koch, F. Graf, S. Bajohr, R. Reimert, Th. Kolb, Renewable Energy, 85, pp.1371-1390 (2016)

5. A. C. Benim, B. Epple, B. Krohmer, Progress in Computational Fluid Dynamics, 5, 6, pp.345-361 (2005)

6. J. P. Kim, U. Schnell, G. Scheffknecht, A. C. Benim, Progress in Computational Fluid Dynamics - An International Journal, 7, 6, pp.337-346 (2007)

7. S. De, A. K. Agarwal, V. S. Moholkar, B. Thallada (Eds.), Coal and Biomass Gasification, (Springer, Berlin, Germany, 2018)

8. IAEA, "Hydrogen Production Using Nuclear" Energy, IAEA Nuclear Energy Series No. NP-T-4.2, Internat. Atomic Energy Agency, Vienna (2013)

9. A. C. Benim, K. J. Syed, Flashback Mechanisms in Lean Premixed Gas Turbine Combustion, (Academic Press, Cambridge, MA, USA, 2015)

10. B. Lewis, G. von Elbe, Combustion, Flames and Explosions of Gases, $3^{\text {rd }}$ ed., (Academic Press, Orlando, USA 1987)

11. H. Philips, Proc. Roy. Soc., 7, pp.129-135 (1963)

12. S. Y. Yang, S. H. Chung, H. J. Kim, Nuclear Engineering and Design, 224, pp.199-206 (2003) 
13. S. W. Hong, J. H. Song, Journal of Nuclear Sci. Techn., 50, pp.1213-1219 (2013)

14. Z. B. Song, L. J. Wei, Z. Z. Wu, Z. Z., Comb. Sci. and Techn., 180, pp.264-278 (2008)

15. S. Kudriakov, E. Studer, C. Bin, International J. Hydrogen Energy, 36, pp.2555-2559 (2011)

16. J. L. Xia, B. L. Smith, A. C. Benim, J. Schmidli, G. Yadigaroglu, Computers \& Fluids, 26, 8, pp.811-823 (1997)

17. A. C. Benim, A. Nahavandi, K. J. Syed, K.J., Progress in Computational Fluid Dynamics - An International Journal, 5, 8, pp.444-454 (2005)

18. A. C. Benim, M. P. Escudier, A. Nahavandi, A. K. Nickson, K. J. Syed, F. Joos, International Journal of Numerical Methods for Heat \& Fluid Flow, 20, 3, pp.348-370 (2010)

19. H. Chattopadhyay, A.C. Benim, Journal of Heat Transfer - Transactions of the ASME, 133, 10, Article Nr.: 104502, 5 pages (2011)

20. P. Oclon, S. Lopata, M. Nowak, A. C. Benim, Progress in Comput. Fluid Dynamics, 15, 5, pp.290306 (2015)

21. A. C. Benim, S. Iqbal. W. Meier, F. Joos, A. Wiedermann, Applied Thermal Engineering, 110, pp.202-212 (2017)

22. S. Iqbal, A. C. Benim, S. Fischer, F. Joos, D. Kluß, A. Wiedermann, Journal of Thermal Science, 25, 5, pp.460-469 (2016)

23. S. R. Turns, An Introduction to Combustion, $3^{\text {rd }}$ ed., (McGrawHill, New York, USA, 2012)

24. R. B. Bird, W. E. Stewart, E. N. Lightfoot, Transport Phenomena, $2^{\text {nd }}$ ed., (Wiley, New York, USA, 2002)

25. A. C. Benim, Computer Methods in Applied Mechanics and Engineering, 67, 1, pp.1-14 (1988)

26. www.ansys.com

27. J. P. Van Doormaal, G. D. Raithby, Num. Heat Trans., 7, pp.147-163 (1984)

28. R. I. Issa, J. Computational Physics, 62, pp.66-82 (1986)

29. H. K. Versteeg, W. Malalasekera, An Introduction to Computational Fluid Dynamics - The Finite Volume Method, $2^{\text {nd }}$ ed., (Pearson, London, UK, 2007)

30. T. J. Barth, D. C. Jespersen, The design and application of upwind schemes on unstuctured meshes, AIAA-89-0366 (1989)

31. B. P. Leonard, Comput. Meths. Appl. Mechanics and Eng., 8, pp.59-98 (1979)

32. www.cantera.org

33. R. J. Kee, F. M. Rupley, J. A. Miller, The Chemkin thermodynamic data base, Sandia Report, SAND878215B (1991)

34. R. A. Shevla, Estimated viscosities and thermal conductivities of gases at high temperatures, NASA Technical Report R-132 (1962)
35. R. C. Reid, J. M. Prausnitz, B. E. Poling, The Properties of Gases and Liquids, $4^{\text {th }}$ ed., (McGrawHill, New York, USA, 1987)

36. P. Gerlinger, Numerische Verbrennungssimulation, (Springer, Berlin, Germany. 2005)

37. V. P. Zhukov, International Scholarly Research Network, Article ID 475607, 11 pages (2012)

38. N. M. Marinov, C. K. Westbrook, W. J. Pitz, Detailed and global chemical kinetics model for hydroge", Report No. UCRL-JC-120677, Lawrence Livermore National Laboratory, California, USA (1995)

39. M. O. Conaire, H. J. Curran, J. M. Simmie, W. J. Pitz, C. K. Westbrook, International Journal of Chemical Kinetics, 36, pp.603-622 (2004)

40. H. C. Barnett, R. R. Hibbard (Eds.), Basic considerations in the combustion of hydrocarbon fuels with air, NACA Report 1300 (1959) 